\title{
Effect of visualization and subvocalization on
}

\section{perceptual clarity}

\author{
LIONEL STANDING, ${ }^{2}$ CAROL SELL, \\ JUDITH BOSS, ${ }^{3}$ and RALPH NORMAN \\ HABER, University of Rochester, \\ Rochester, N.Y. 14627
}

To determine the effect of various kinds of internal representations of a stimulus upon its perceived clarity, six Ss were shown five flashes of single letters under each of six conditions. In five of them, $S$ was told the letter before the first flash and then asked to visualize it during the flashes, to subvocalize it, to visualize another letter (also told to him), to subvocalize another letter, or to do nothing. The sixth condition provided no prior knowledge of the letter to be flashed. Exposures were set just above threshold, so that on the first flash, only minimal clarity was achieved. The results showed that clarity increased over the five repetitions for all six conditions at the same rate. The greatest clarity occurred when $S$ imagined (in either manner) the letter being presented and the least when he imagined a different letter. Prior knowledge alone was not different from no prior knowledge, and both of these conditions fell between the other two sets of conditions. Thus, prior knowledge apparently does not affect perceptual clarity directly but only by permitting visual and auditory imagery to occur during presentation. These results were taken to support a model of perceptual recognition offered by Haber (1969).

It has been repeatedly demonstrated that several well-spaced flashes of a letter will increase its perceptual clarity and recognizability. Haber (1969) provides a summary of this research and a brief description of a model covered by the results. Haber, Standing, \& Boss (1969) have recently shown that this effect is not likely to be due to a sensory enhancement.

The present experiment is concerned with the effects of possible internal representations of the test stimulus upon recognition. While prior knowledge is known to facilitate recognition (Haber, 1965; Hershenson, 1969), it is not known whether or not $\mathrm{S}$ must store this knowledge in some particular form for it to be effective as, for example, a visual or auditory image. To study this, Ss were shown the same letter repeatedly while they either visualized or subvocalized the test letter during its five repetitions or visualized or subvocalized a different letter. In each of these conditions, prior knowledge of the stimulus was provided before the first flash. In another condition, the Ss were also given prior knowledge of the stimulus but told to refrain from all visualizing and subvocalizing. Finally, tested without prior knowledge, Ss were permitted to visualize and subvocalize anything they wished.

\section{SUBJECTS}

Six experimentally naive students, with normal or corrected vision, were used as paid Ss. All reported that they were able to produce some visual imagery and to subvocalize.

\section{APPARATUS AND STIMULI}

The test stimuli were single letters, comprising the letters of the alphabet (except Q). They were printed (in lower-case Univers 55, 18-point) in black on white by means of the Letraset process. Each test letter subtended a maximum vertical visual angle of $0.36 \mathrm{deg}$. The letters were presented in one channel of a two-channel Scientific Prototype tachistoscope (Model 800F). The second channel (illuminated at all times except when the test channel was on) provided a fixation region, in which the central portion (1 deg wide) of an upright black cross was omitted. Both channels were set at $2.0 \mathrm{~mL}$. The $\mathrm{S}$ initiated the flash when he was ready.

\section{PROCEDURE}

Each $S$ was tested under each of the six conditions (see below), according to a 6 by 6 Latin square, one condition per daily session. Every session commenced with a measurement of S's daily threshold level, defined as the test stimulus duration yielding a 0.5 probability of correct forced-choice identification after a single test stimulus presentation. Testing was then performed, with the test stimulus duration $10 \%$ above the daily threshold value. This typically approximated $7 \mathrm{msec}$. Each session lasted less than $1 \mathrm{~h}$.

Following the threshold measurement, $S$ was given instructions appropriate to the condition being employed, and tested with the 25 test stimuli. Five repetitions of each letter were given, with an interflash interval of approximately $5 \mathrm{sec}$. The $\mathrm{S}$ verbally rated the clarity of the stimulus after each presentation, using a 5-point scale: 1-nothing seen; 2-some indistinct, faint pattern seen; 3-some fragments of the letter's contours visible; 4-a moderately sharp outline of the letter seen, but insufficiently for certain identification of the letter; 5-almost perfect clarity, definitely sufficient to identify the letter. It was emphasized that the clarity ratings should be given solely on the basis of the sharpness or blackness of the perceived form and not on the S's confidence of recognition of the form. The test letters were presented in alphabetic sequence for all conditions except the one with no knowledge, in which they were shown in a random order of which $S$ had no prior knowledge.

The $S$ was instructed under the visualize and subvocalize conditions, respectively, to hold a visual image of the test letter in his consciousness or to subvocalize the letter silently to himself before initiating each test-stimulus presentation. For two other conditions, he was instructed, respectively, to visualize or to subvocalize a different randomly determined letter that would be read aloud by $E$ before the first presentation of each test stimulus. Under the knowledge-only condition, he was instructed to attend to the test stimulus as before but to refrain from holding any visual or auditory image of it before or after presentations. For each of these five conditions, $S$ was told that the stimuli would follow alphabetic sequence (with $Q$ missing), and the $E$ would remind $S$ of the identity of a given test stimulus should he forget it. There was no evidence that $S$ ever forgot the name of the test letter, even while imagining some other letter. Under the no-knowledge condition, $S$ was told that the same alphabetic stimuli would be shown in an unpredictable order, and that he could, if he wished, visualize or subvocalize the letter (when he was able to recognize it). It was emphasized that while there were no "right" or "wrong" responses, $S$ 's full cooperation was essential to the experiment.

\section{RESULTS}

An initial analysis of variance indicated that the mean clarity ratings were not reliably affected by practice effects between the testing sessions $(F<1)$ or by differences between $S s \quad(F=1.92$, $\mathrm{d} f=5 / 20, p>.05$ ). Figure 1 presents the condition by repetition results. The six experimental conditions produced reliable mean differences $(F=8.5, d f=5 / 100$, $p<.01)$, as did the effect of repetition $(F=10.9, d f=4 / 100, p<.01)$.

The analysis of variance showed that the upward trend in clarity did not interact with conditions $(\mathrm{F}=1.41, \mathrm{df}=20 / 100$, $p>.05$ ). The mean differences between conditions were examined by means of Duncan's multiple-range test (with $\alpha=.01$ ), which showed that significant differences did not exist within the following pairs of conditions: visualize and subvocalize, knowledge-only and no-knowledge, and visualize and 


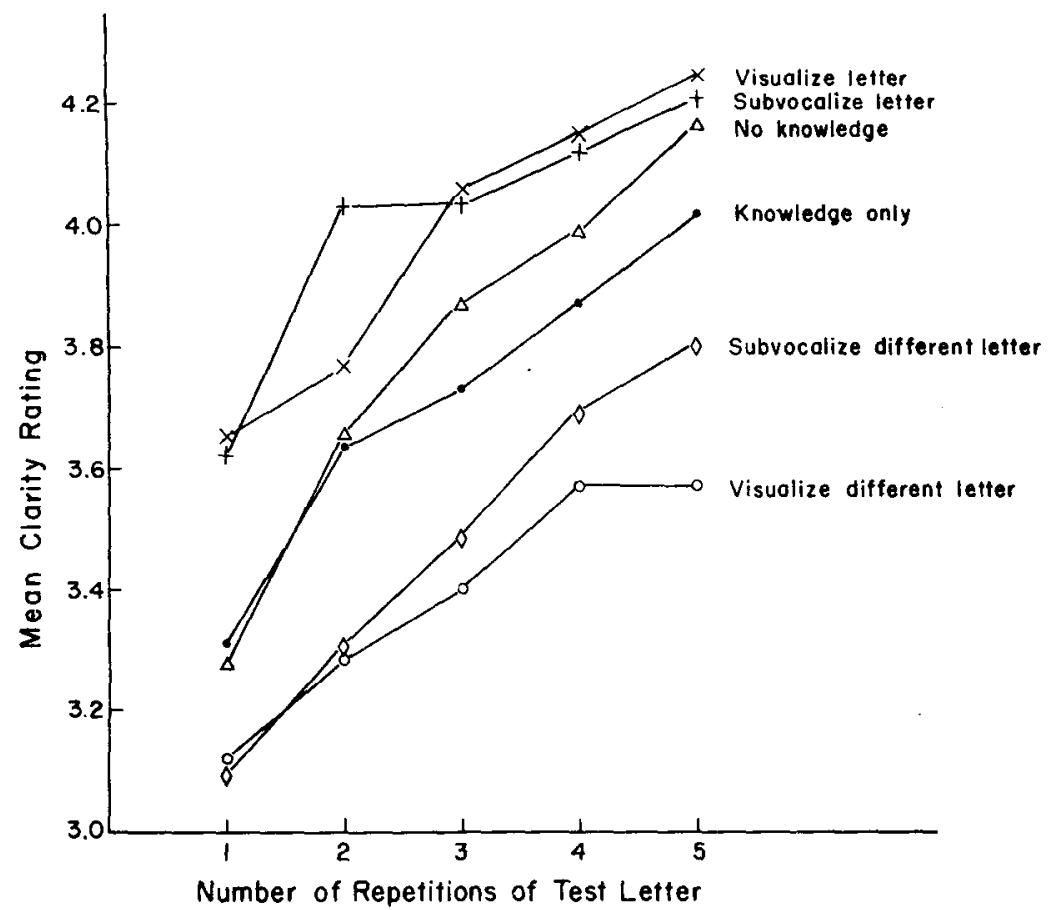

subvocalize a different letter. All other differences between conditions were significant. While a significant $S s$ by Conditions interaction was found $(\mathrm{F}=19.5, \mathrm{df}=25 / 100, \mathrm{p}<.01)$, the consistency of the data is indicated by noting that, taking each S's mean no-knowledge score as a control, 20 out of 24 of the observed condition means were in the appropriate direction (i.e., visualize and subvocalize means were higher than that of no-knowledge, while visualize or subvocalize a different letter were lower). Thus, this interaction reflects differences in slopes rather than in the relative ordering of the conditions.

\section{DISCUSSION}

Although it is usual to ignore the state of the $\mathrm{S}$ in most perception studies (with the exception of motivational studies and experiments on set) beyond specifying that he be attentive, the present data suggest that S's internal processes are quite important in determining his percepts. The experiment may thus be placed with other studies that have emphasized the significance of imagery-related processes in perception, performance, and learning (e.g., Perky, 1910; Brooks, 1967; Paivio, in press).

We assume that the observed differences are not simply the result of response bias-S saying a letter is clearer because he knows what it is. If this were the case, we should have expected the no-knowledge condition to be lower than the other five conditions, with few differences among the remaining ones.
Haber (1965) and Hershenson (1969) each found that S's ability to see the letters of seven- and eight-letter words was improved when prior knowledge was given prior to the first presentation. No such simple effect was found here for single letters in that the knowledge-only and the no-knowledge conditions did not differ. Thus, the simple prior-knowledge manipulation (without the other variables studied in this experiment) does not appear to be effective when the stimuli are only single letters.

This study suggests that perceptual growth from repetition is apparently unaffected by imagery, since all six conditions show the same rate of growth. However, the facilitation of perception by prior knowledge of the stimulus (Haber, 1965; Hershenson, 1969) seems to be due to visual or auditory imagery of the test stimulus being induced by the prior information and not due to the knowledge itself. Particularly important is the finding that clarity under the knowledge-only and the no-knowledge conditions is virtually identical on the first trial, while both the visualize and the subvocalize conditions yield a clearer percept. Prior knowledge without imagery appears to be as ineffective as no knowledge at all. Conversely, the percept of the test letter appears to be reduced in clarity when $S$ visualizes or subvocalizes a different letter while flashing the test stimulus, even though he has prior knowledge of the test letter's identity.

Granted the assumptions of the measurement technique, the results are
Fig. 1. Mean rated clarity of test stimuli over five repeated flashes, for the six Ss combined, for six different experimental conditions.

compatible with Haber's (1969) view of perceptual growth as analogous to the growth of a cell assembly. Thus, repetition of a barely adequate stimulus results in the progressively greater arousal of the appropriate assembly, which, in turn, improves its perceptual clarity. Repetition appears to increase assembly arousal whether or not prior knowledge is given, or whether or not the $\mathbf{S}$ employs imagery during the stimulation. However, the repetitions are more effective if $S$ uses prior knowledge to imagine the stimulus as it is being presented, and they are less effective if $S$ imagines a different letter from the one being shown. Thus, it appears as if the prior-knowledge effect on the growth of percepts is mediated by the nature of the imagery $S$ engages in during the presentations.

Of perhaps some interest is the similarity of the effects of visualizing and subvocalizing. Either Ss are unable to differentiate their imaginations by modality or the arousal effect from imagining occurs after input channels are combined.

\section{REFERENCES}

BROOKS, L. R. The suppression of visualization by reading. Quarterly Joumal of Experimental Psychology, 1967, 19, 289-299.

HABER, R. N. Effect of prior knowledge of the stimulus on word-recognition processes. Journal of Experimental Psychology, 1965, 69, 282-286.

HABER, R. N. Repetition as a determinant of perceptual recognition processes. In $W$. Wather-Dunn (Ed.), Symposium on models for the perception of speech and visual form. Cambridge: M.I.T. Press, 1967. Pp. 202-212.

HABER, R. N. Repetition, visual persistence, visual noise, and information processing. In $K$. N. Leibovic (Ed.), Information processing in the nervous system. Columbus: Springer, in press.

HABER, R. N., STANDING, L. G., \& BOSS, J. Effect of position and typeface variation on perceptual clarity. Psychonomic Science, $1970,18,91-92$.

HERSHENSON, M. Stimulus structure, cognitive structure, and the perception of letter arrays. Journal of Experimental Psychology, 1969, 79, 327-335.

PAIVIO, A. Mental imagery in ${ }^{-}$associative learning and memory. Psychological Review, in press.

PERKY, C. An experimental study of imagination. American Journal of Psychology, $1910,23,422-452$.

\section{NOTES}

1. This research was supported in part by grants from the United States Public Health Service, MH 10753, and from the National Science Foundation, GB 5910, to the fourth author.

2. Now at Bishop's University, Lennoxville, Quebec, Canada.

3. Now at Dalhousie University, Nova Scotia, Canada. 